\title{
Choroid Plexus Carcinoma in Adults: Two Case Reports
}

\author{
Taehoon Kim¹, Mee Rim Park², Eun Kyeong Hong ${ }^{3}$, Ho-Shin Gwak ${ }^{4}$ \\ 'Department of Neurosurgery, Seoul National University College of Medicine, Seoul, Korea \\ ${ }^{2}$ Center for Pediatric Cancer, National Cancer Center, Goyang, Korea \\ ${ }^{3}$ Department of Pathology, National Cancer Center, Goyang, Korea \\ ${ }^{4}$ Deaprtment of Cancer Control, National Cancer Center, Graduate School of Cancer Science and Policy, Goyang, Korea
}

Received October 17, 2018

Revised March 10, 2019

Accepted March 28, 2019

\section{Correspondence}

Ho-Shin Gwak

Department of Cancer Control, National Cancer Center, Graduate School of

Cancer Science and Policy, 323 Ilsan-ro, Ilsandong-gu, Goyang 10408, Korea

Tel: +82-31-920-1666

Fax: +82-31-920-2798

E-mail: nsghs@ncc.re.kr

\begin{abstract}
Choroid plexus tumors are uncommon brain tumors that primarily occur in children. Most of these tumors originate from the intraventricular area, and the most common clinicalpresentation is increased intracranial pressure. Dissemination through the cerebrospinal fluid space is the inevitable natural course of the disease. Here, we present 2 rare cases of adult choroid plexus carcinoma (CPC), each with distinct clinical presentation and progression. The first case was a 40-year-old male who presented with multiple intraventricular masses. After surgical biopsy, radiation and intrathecal chemotherapy failed to elicit any response. The patient progressed with spinal cord dissemination and expired 1 year later. The second case presented with visual disturbance, and brain MRI revealed a large ovoid juxtaventricular mass with peritumoral edema. This 49-year-old female patient underwent craniotomy for what was thought to be a high-grade glioma; however, the mass was connected to the choroid plexus at the operative field. Her pathology specimen was diagnosed as CPC, and adjuvant systemic chemotherapy was administered. She has now been free of recurrence for 10 months. The description of the presentation and progression of these rare adult-onset CPC provides insight for the diagnosis and treatment of other rare instances of choroid plexus tumors.
\end{abstract}

Key Words $\quad$ Adult; Cerebrospinal fluid; Choroid plexus carcinoma; Fourth ventricle.

\section{INTRODUCTION}

Choroid plexus tumors are rare, accounting for only $0.3^{-}$ $0.6 \%$ of all brain tumors and $10-20 \%$ of those in infants [1]. Choroid plexus tumors include choroid plexus papilloma (CPP), atypical CPP, and choroid plexus carcinoma (CPC). Of these subtypes, CPCs are the most aggressive and malignant at a World Health Organization grade III. CPC primarily occurs in children, and the median age of patients with CPC is 3 years, highlighting the rarity of adult-onset CPC. As CPC is derived from choroid plexus epithelium, it usually presents with cerebrospinal fluid (CSF) obstruction and progresses through CSF metastasis [1-3]. Mechanical obstruction of the CSF is a common cause of symptoms, including headache, diplopia, and ataxia, and is followed by hydrocephalus [4]. Because of their

This is an Open Access article distributed under the terms of the Creative Commons Attribution Non-Commercial License (https://creativecommons.org/licenses/by-nc/4.0) which permits unrestricted non-commercial use, distribution, and reproduction in any medium, provided the original work is properly cited.

Copyright $\odot 2019$ The Korean Brain Tumor Society, The Korean Society for NeuroOncology, and The Korean Society for Pediatric Neuro-Oncology origin in the choroid plexus epithelium, the majority of CPCs are located within the ventricle. A diffuse border between the tumor and normal brain tissue reflects brain invasion. Maximal surgical resection followed by adjuvant chemotherapy and radiotherapy is the recommended treatment but has yet to be standardized [5].

Here, we report 2 rare cases of adult CPC, which exhibited differing clinical presentation: multiple ventricular seeding and a single juxtaventricular mass. The institutional review board exempt any informed consent from the patients unless the retrospective study reveal personal identifiable information.

\section{CASE REPORT}

\section{Case 1}

A 40-year-old man who was diagnosed with CPC and leptomeningeal seeding visited our outpatient clinic for a second opinion. The medical history revealed that his chief complaint was dizziness, nausea, and headache, and brain MRI revealed nodular lesions at the 4 th ventricle and tectum (Fig. 1). Sub- 


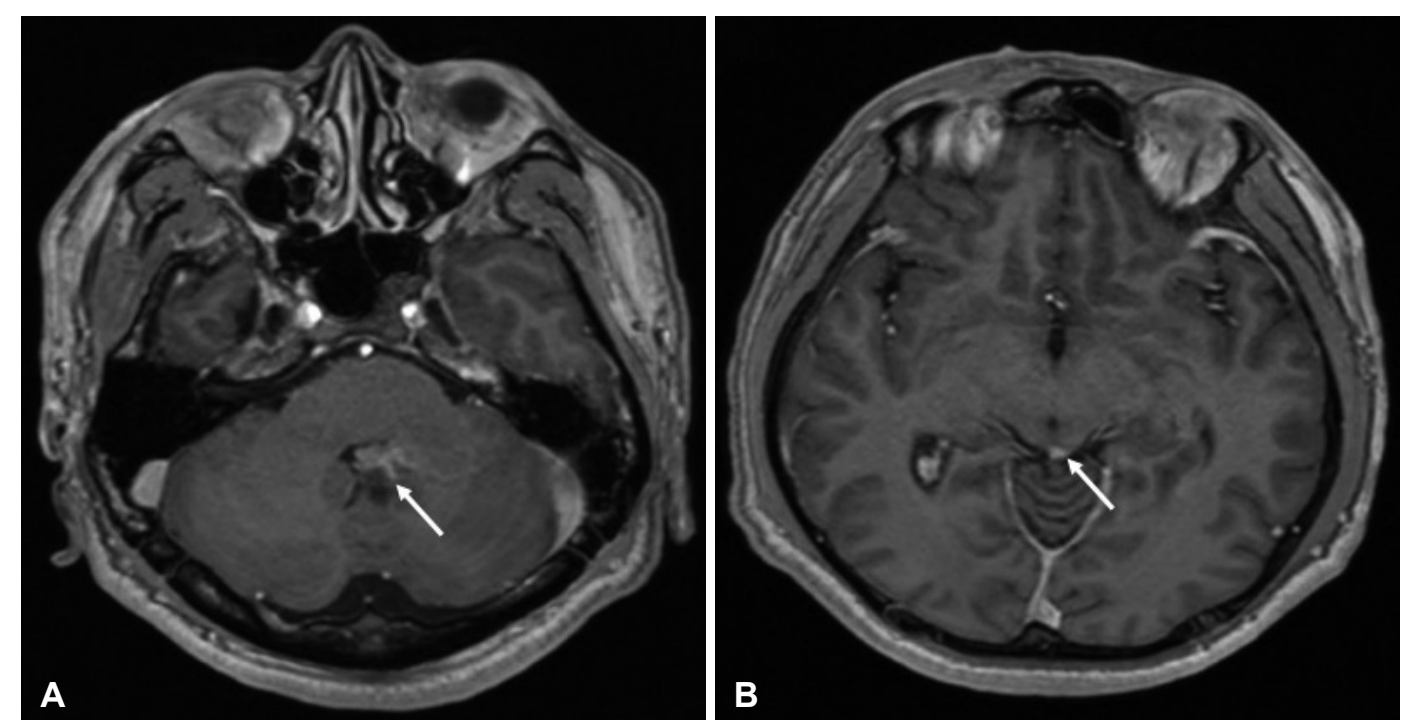

Fig. 1. T1-weighted gadolinium enhanced brain MRI revealed enhancing masses (A) on the 4th ventricular floor (arrow), and (B) around the tectum (arrow), (case 1).

total removal of 4th ventricular mass was performed, and the pathologic diagnosis was CPC. After the surgery, he complained of sacral area pain. T1-weighted gadolinium enhanced spine MRI showed linear nodular enhancement of whole spinal cord surface, which was compatible of disseminated spinal metastasis (Fig. 2), and CSF cytology was positive for malignant cells. Craniospinal irradiation of 3,600 cGy was delivered in 12 fractions, but the patient progressed to show cauda equina syndrome. Follow-up spine MRI presented aggravated leptomeningeal seeding, and nivolumab was administered as additional salvage chemotherapy. Unfortunately, the patient continued to suffer from worsening symptoms.

Neurological exam at the time of admission to our clinic, 7 months after the brain surgery, showed left side lower extremity weakness of motor grade 4 out of 5 with saddle hypoesthesia, right facial palsy, and facial hypoesthesia. Systemic etoposide and carboplatin (CPT-SIOP-2000) chemotherapies were given [6], and intrathecal methotrexate was administered 4 weeks after the chemotherapy in 2 treatments [7]. However, the patient could get neither symptom improvement nor cytological/radiological response. He deferred any further treatment with slow progression of existing neurological deficiency. Four months after the intrathecal chemotherapy, the patient expired.

\section{Case 2}

A 49-year-old woman was transferred to our emergency room from another hospital for treatment of an alleged malignant brain tumor. Her chief complaint was visual field disturbance, and she had experienced a generalized tonic-clonic seizure a week prior. She presented right side homonymous hemianopsia upon visual field test (Fig. 3A), and papilledema was observed with fundoscopy.

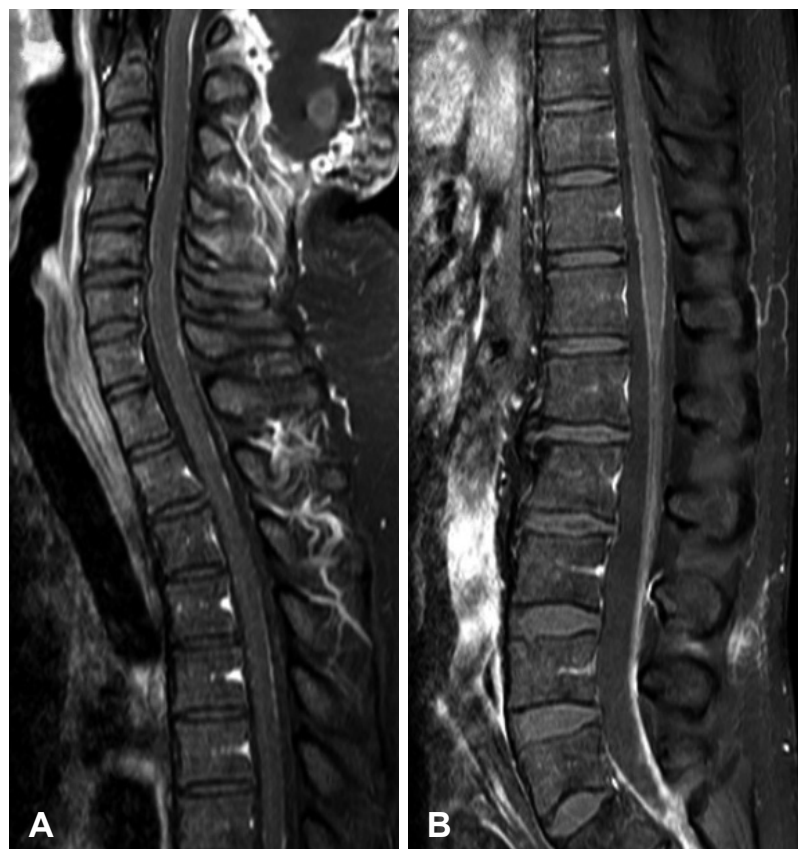

Fig. 2. T1-weighted gadolinium enhanced spine MRI showed multiple linear nodular enhancements of (A) cervicothoracic spinal cord surface, and (B) conus medullares, suggesting leptomeningeal metastases (case 1).

Brain CT revealed a large (diameter of $4 \mathrm{~cm}$ ) iso-dense intra-axial ovoid mass in the left temporo-occipital area (Fig. 4A). A T2-weighted brain MRI revealed that the mass contained an internal cystic region, abutted the choroid plexus, and had potentially invaded the trigone of the lateral ventricle (Fig. 4B, C). Gadolinium enhancement showed homogenous enhancement of the solid portion, suggesting that the mass was a high-grade glioma or metastatic tumor (Fig. 4D). The radiologist recommended both MR spectroscopy and a metastasis work-up. MR 
spectroscopy revealed a high choline peak that was consistent with malignant tumors (Fig. 4E). However, the metastasis workup, including whole-body positron emission tomography, colonoscopy, and esophagogastroduodenoscopy, was negative for systemic primary cancer.
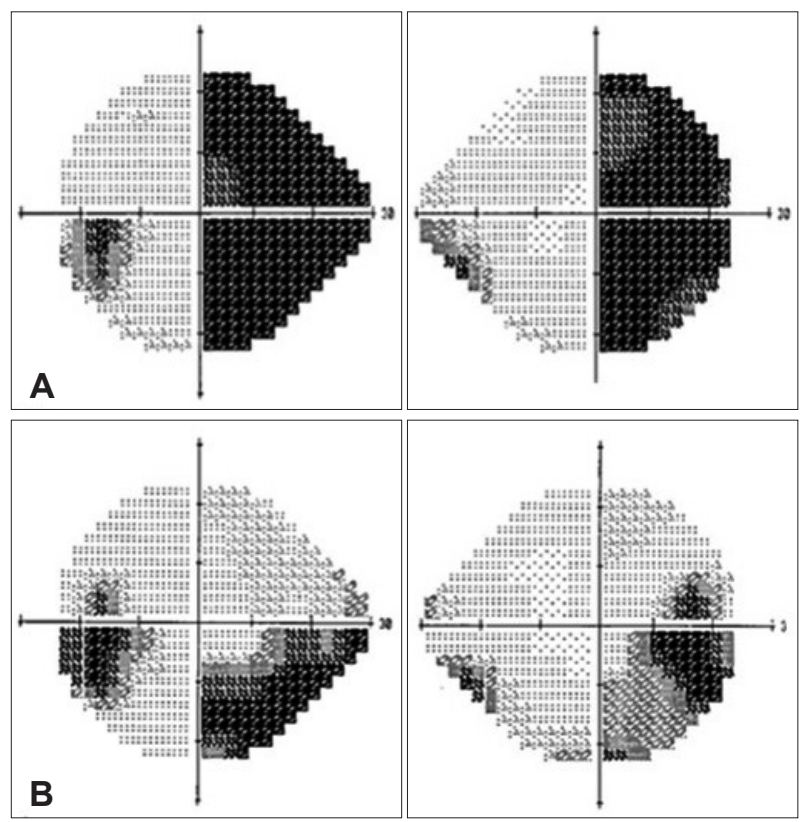

Fig. 3. Goldmann perimetry of case 2. A: Preoperative visual field test revealed right side homonymous hemianopsia. B: Postoperative 3-month follow-up test showed a largely resolved visual field defect (case 2).
Tumor removal was performed with a transcortical approach via the parieto-occipital junction. The resected tumor was covered with a glistening capsule and was found to be attached to the choroid plexus at the end of the removal. Intraventricular hemorrhage was observed immediately postoperation via a brain CT, and gadolinium enhanced brain MRI confirmed the gross total removal of the tumor 24 hours after the operation (Fig. 5).

Histologically, the tumor was well-encapsulated with a distinct fibrous capsule and was composed of columnar epithelial cells on fibrovascular cores (Fig. 6A, B). The tumor cells had prominent nuclear pleomorphism, suggestive of a carcinoma. Immunohistochemically, tumor cells were focally positive for epithelial membrane antigen and transthyretin (Fig. 6C). Moreover, tumor cells were positive for synaptophysin and negative for other marker including glial fibrillary acidic protein and vimentin. The Ki-67 index was $21.66 \%$. Altogether, these results led to a final diagnosis of CPC. Based on this diagnosis, whole-spine MRI and CSF cytology were performed, and both tests were negative for leptomeningeal seeding.

Right side homonymous hemianopsia gradually improved during follow-up and was largely resolved at postoperative 3 months (Fig. 3B). After consultation with a pediatric oncologist, the patient received 4 cycles of carboplatin-etoposide chemotherapy without any severe side effects. The patient showed neither radiological nor clinical signs of progression at postoperative 10 months.
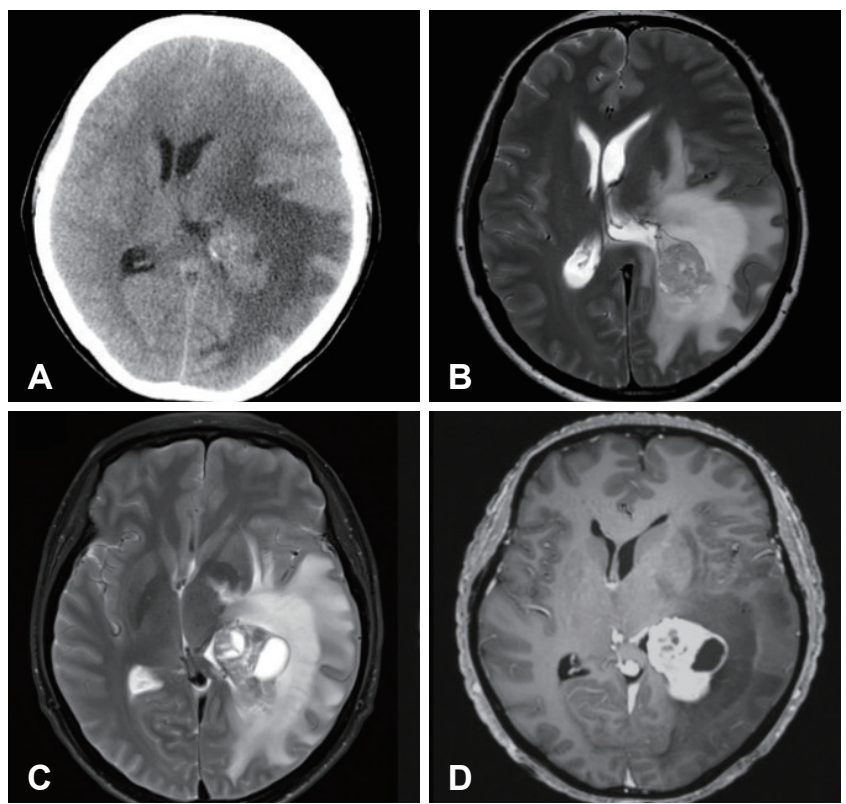

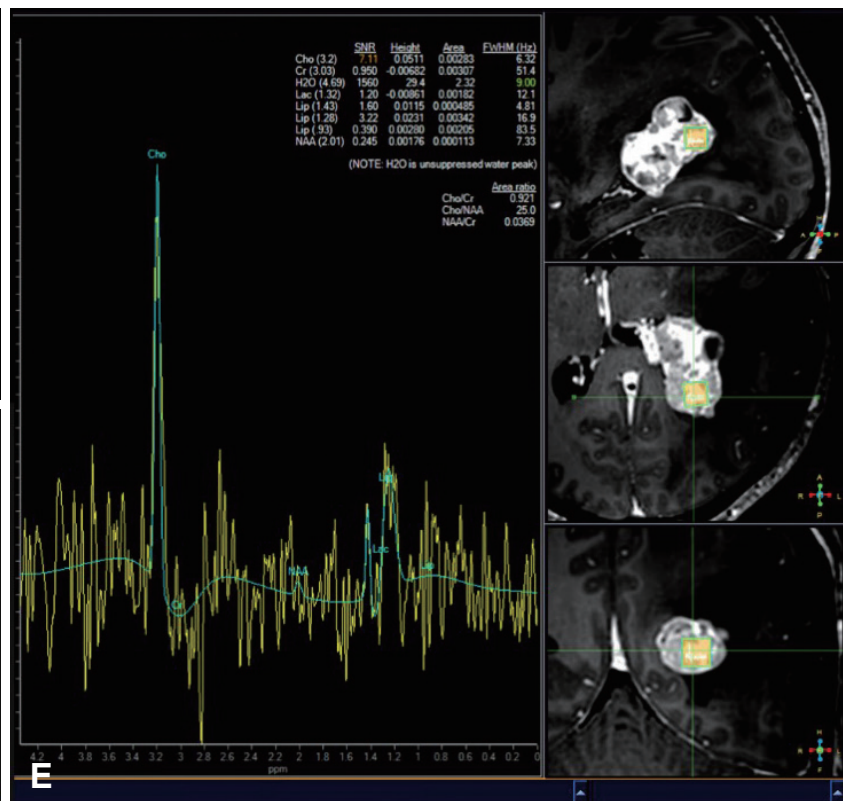

E

Fig. 4. Preoperative brain image of the patient (case 2). The mass was located on the trigone of the left lateral ventricle. CT showed an isodense mass with peritumoral edema (A). T2-weighted (B, C) and T1-weighted (D) gadolinium enhanced brain MRI revealed a well-enhanced juxtaventricular parenchymal mass with an internal cystic portion. MR spectroscopy demonstrated an elevated choline peak, suggesting a malignant tumor (E). 

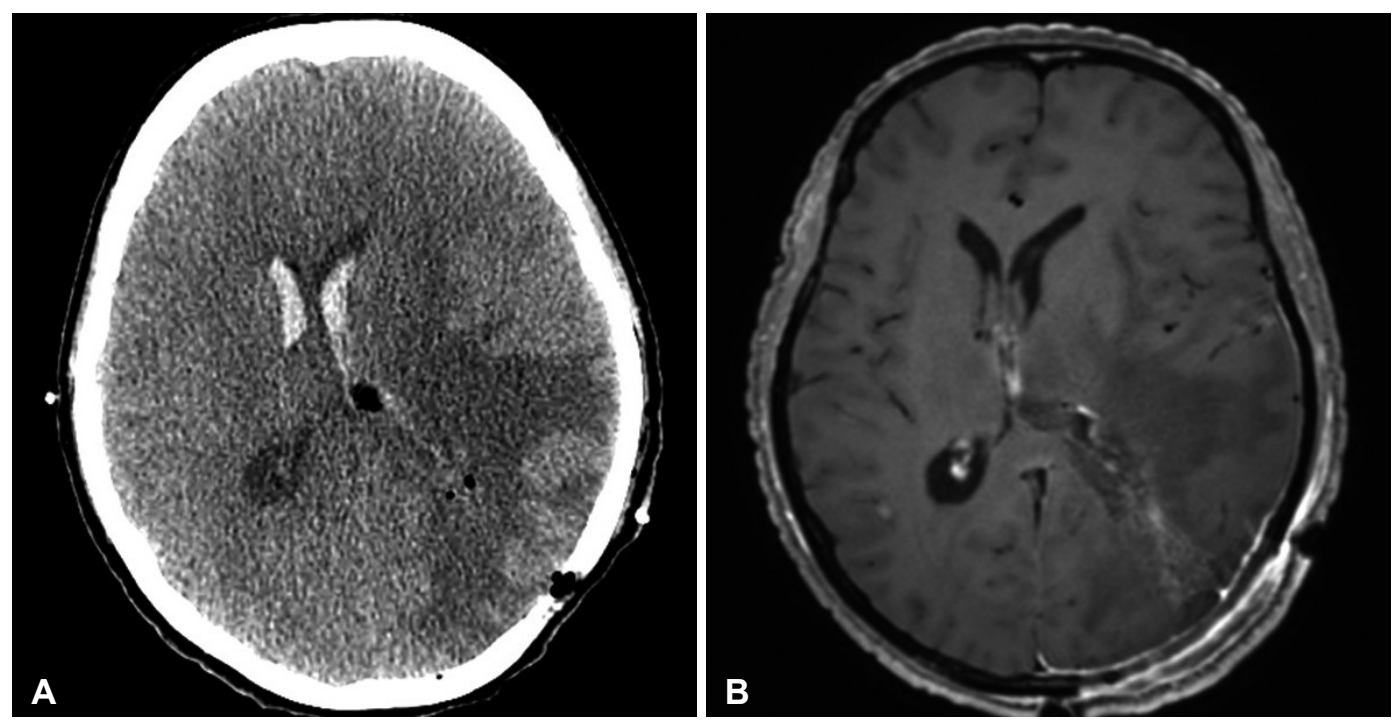

Fig. 5. Postoperative brain image of the patient. A: Immediate postoperative brain CT showed intraventricular hemorrhage. B: T1-weighted gadolinium enhanced images from the postoperative MRI suggested gross total removal of the tumor (case 2).
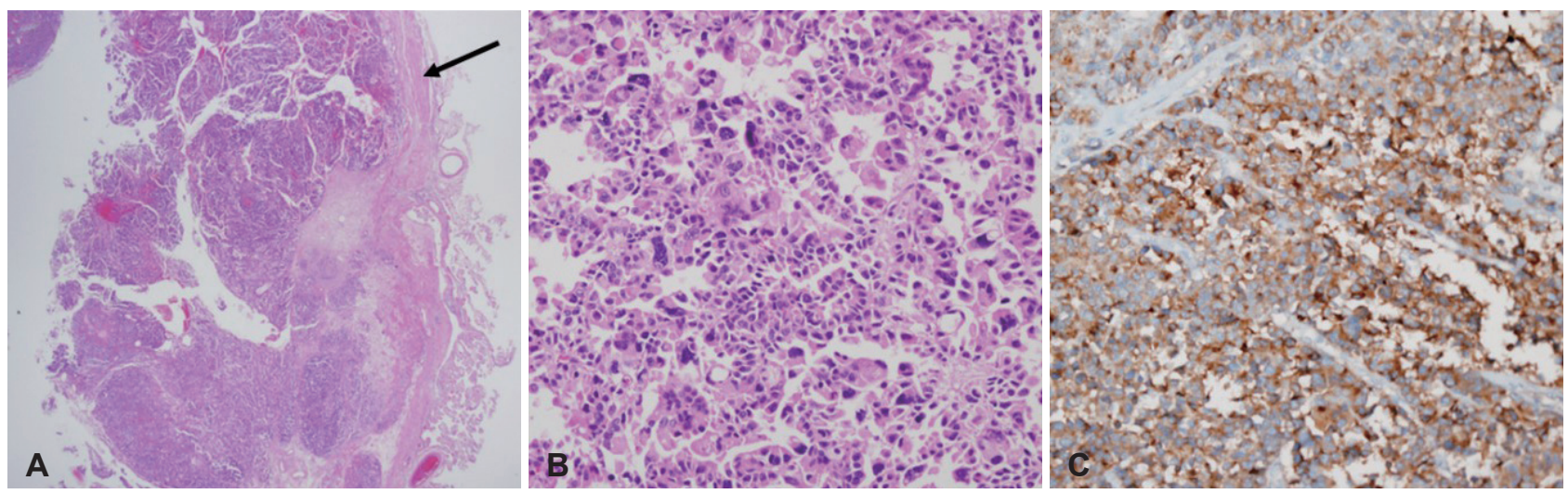

Fig. 6. Photomicrographs of surgical specimens (case 2). A: The tumor was well-encapsulated with a distinct fibrous capsule with normal choroid plexus attached (arrow) and showed papillary growth pattern (H\&E stain, $\times 12.5)$. B: The tumor cells were composed of columnar epithelial cells, and some cells had frank nuclear pleomorphism that resulted in a blurred papillary growth pattern (H\&E stain, $\times 200)$. C: Immunohistochemical staining for transthyretin was positive focally $(\times 200)$.

\section{DISCUSSION}

As reviewed by Sun et al. [1], the location of CPCs varies with age. Most lateral ventricular tumors occur in patients younger than 20 , whereas 4 th ventricular CPCs are evenly distributed amongst all age groups. Presentation with multiple CPCs is relatively rare, occurring in only $5 \%$ of CPC patients. The first case in this report presented with 4th ventricular CPC and a tectal mass at 40 years of age. For lateral and 3 rd ventricle CPCs, the median age of presentation is 1.5 years, and supratentorial CPCs are extremely rare in adults. In fact, we could only retrieve 4 cases from the literature [8-11], which are summarized in Table 1. The second case presented here was diagnosed at age 49 , and the location of the tumor was more consistent with 'extraventricular' than lateral ventricle. Differential diagnosis based on imaging characteristics are difficult in extraventricu- lar cases of CPC as well as CPP, choroid plexus cyst, ependymoma, primitive neuroectodermal tumor, astrocytoma, germinoma, teratoma, meningioma, metastasis to the choroid plexus, and xanthogranuloma [1]. Differential diagnosis is further complicated by the increased tendency of CPCs to invade the parenchyma.

$\mathrm{CPC}$ is associated with poor prognosis, and the 5 -year survival rate for patients with CPCs is approximately $40 \%$ [12]. Numerous authors have emphasized the importance of gross total removal of CPC as part of the therapeutic strategy $[1,3,8,9,13]$. The extent of tumor removal is associated with significantly superior overall survival (OS); whereas, the effect of adjuvant chemotherapy or radiotherapy on OS remains controversial [14]. Based on meta-analysis of Wolff et al. [13], adjuvant radiation can improve survival even after gross total resection; however, this effect was only statistically significant in older 
Table 1. Summary of adult supratentorial choroid plexus carcinomas from the literature

\begin{tabular}{|c|c|c|c|c|c|}
\hline Study & $\begin{array}{l}\text { Sex/ } \\
\text { age }\end{array}$ & Location & $\begin{array}{c}\text { Surgical } \\
\text { result }\end{array}$ & $\begin{array}{l}\text { Adjuvant } \\
\text { treatment }\end{array}$ & Outcome \\
\hline $\begin{array}{l}\text { Guo et al. } \\
{[8]}\end{array}$ & $\mathrm{M} / 59$ & $\begin{array}{l}\text { Extraventricular, } \\
\text { temporoparietal lobe }\end{array}$ & GTR & $\begin{array}{l}\text { Chemotherapy } \\
\text { +radiation }\end{array}$ & Recurred 6 months after operation \\
\hline $\begin{array}{l}\text { Lozier et al. } \\
\text { [9] }\end{array}$ & $\mathrm{F} / 68$ & $\begin{array}{l}\text { Extraventricular, } \\
\text { anterior temporal lobe }\end{array}$ & GTR & $\begin{array}{l}\text { Chemotherapy } \\
\text { +radiation }\end{array}$ & $\begin{array}{l}\text { No evidence of recurrence or residual } \\
\text { tumor } 44 \text { months after operation }\end{array}$ \\
\hline $\begin{array}{l}\text { Bohara et al. } \\
{[10]}\end{array}$ & & Trigone of lateral ventricle & GTR & $\begin{array}{l}\text { Chemotherapy } \\
\text { +radiation }\end{array}$ & Expired 13 months after operation \\
\hline $\begin{array}{l}\text { Yip et al. } \\
{[11]}\end{array}$ & & Lateral ventricle and trigone & GTR & $\begin{array}{l}\text { Chemotherapy } \\
\text { +radiation }\end{array}$ & $\begin{array}{l}\text { No evidence of recurrence } 2 \text { years } \\
\text { after operation }\end{array}$ \\
\hline $\begin{array}{l}\text { This study } \\
\text { (case 2) }\end{array}$ & $\mathrm{F} / 49$ & $\begin{array}{l}\text { Extraventricular, } \\
\text { temporoparietal lobe }\end{array}$ & GTR & Chemotherapy only & $\begin{array}{l}\text { No evidence of recurrence } 10 \text { months after } \\
\text { operation }\end{array}$ \\
\hline
\end{tabular}

GTR, gross total removal

age young patients (3-9 years old) and not in infants. Adjuvant radiation is also used in cases with leptomeningeal dissemination and spinal metastases. Nevertheless, there is no definite established protocol for radiation or chemotherapy in CPC. Current CPC treatment is based on data from pediatric patients who are heavily treated with chemotherapy, and the role of chemotherapy has not been established in adult CPCs $[1,6,15]$. Evidence from the few reported cases of adult-onset CPC suggests that, even after gross total removal of the lesion with adjuvant chemotherapy or radiotherapy, the outcome of adult CPC varies (Table 1).

In the cases presented here, CPC patients were treated by surgical resection and adjuvant chemotherapy and/or radiotherapy. In case 1, the patient was treated with craniospinal irradiation after craniotomy for spinal metastasis. As spinal metastasis progressed even with radiation, adjuvant chemotherapy was administered for systemic control. The treatment response was poor, and the patient expired within a year. On the other hand, in case 2 , the operation was performed with gross total resection of the lesion, and postoperative spinal images and CSF studies showed no evidence of CSF metastasis. Adjuvant chemotherapy was administered for systemic control without any severe side effects, and there was no sign of progression of the disease up to 10 months postoperation. It is evident that further studies are necessary to establish standardized radiation and chemotherapy strategies in adult CPC patients.

\section{Conflicts of Interest}

The authors have no potential conflicts of interest.

\section{Acknowledgments}

This research was supported by a grant of the Korea Health Technology R\&D Project through the Korea Health Industry Development Institute (KHIDI), funded by the Ministry of Health \& Welfare, Republic of Korea (grant no: HI17C1018).

\section{REFERENCES}

1. Sun MZ, Oh MC, Ivan ME, et al. Current management of choroid plexus carcinomas. Neurosurg Rev 2014;37:179-92.

2. Ozdogan S, Gergin YE, Gergin S, et al. Choroid plexus carcinoma in adults: an extremely rare case. Pan Afr Med J 2015;20:302.

3. Bahar M, Hashem H, Tekautz T, et al. Choroid plexus tumors in adult and pediatric populations: the Cleveland Clinic and University Hospitals experience. J Neurooncol 2017;132:427-32.

4. Sav A, Scheithauer BW, Mazzola CA, Ketterling SR, Thompson SJ, Reilly MH. Oncocytic choroid plexus carcinoma: case report. Clin Neuropathol 2010;29:14-20.

5. Chow E, Reardon DA, Shah AB, et al. Pediatric choroid plexus neoplasms. Int J Radiat Oncol Biol Phys 1999;44:249-54.

6. Wrede B, Hasselblatt M, Peters O, et al. Atypical choroid plexus papilloma: clinical experience in the CPT-SIOP-2000 study. J Neurooncol 2009;95:383-92.

7. Gwak HS, Lee SH, Park WS, Shin SH, Yoo H, Lee SH. Recent advancements of treatment for leptomeningeal carcinomatosis. J Korean Neurosurg Soc 2015;58:1-8.

8. Guo P, Tang W, Li S, et al. Choroid plexus carcinoma in the external ventricle of an adult. J Craniofac Surg 2015;26:e664-6.

9. Lozier AP, Arbaje YM, Scheithauer BW. Supratentorial, extraventricular choroid plexus carcinoma in an adult: case report. Neurosurgery 2009; 65:E816-7.

10. Bohara M, Hirabaru M, Fujio S, et al. Choroid plexus tumors: experience of 10 cases with special references to adult cases. Neurol Med Chir (Tokyo) 2015;55:891-900.

11. Yip CM, Tseng HH, Hsu SS. Choroid plexus carcinoma: a rare tumor in adult. Surg Sci 2014;5:146-9.

12. Gopal P, Parker JR, Debski R, Parker JC Jr. Choroid plexus carcinoma. Arch Pathol Lab Med 2008;132:1350-4.

13. Wolff JE, Sajedi M, Coppes MJ, Anderson RA, Egeler RM. Radiation therapy and survival in choroid plexus carcinoma. Lancet 1999;353:2126.

14. Cannon DM, Mohindra P, Gondi V, Kruser TJ, Kozak KR. Choroid plexus tumor epidemiology and outcomes: implications for surgical and radiotherapeutic management. J Neurooncol 2015;121:151-7.

15. Fabi A, Salesi N, Di Cocco B, et al. Choroid plexus carcinoma in the adult: is there a role for chemotherapy? J Exp Clin Cancer Res 2005;24: 493-6. 